University of Warwick institutional repository: http://go.warwick.ac.uk/wrap This paper is made available online in accordance with publisher policies. Please scroll down to view the document itself. Please refer to the repository record for this item and our policy information available from the repository home page for further information.

To see the final version of this paper please visit the publisher's website. Access to the published version may require a subscription.

Author(s): R G Watt, K I Tull, R Hardy, M Wiggins, Y Kelly, B Molloy, E Dowler, J Apps and P McGlone

Article Title: Effectiveness of a social support intervention on infant feeding practices: randomised controlled trial

Year of publication: 2009

Link to tpublished version: http://dx.doi.org/ 10.1136/jech.2008.077115

Publisher statement: None 


\section{JECH}

\section{Effectiveness of a social support intervention on infant feeding practices: randomised controlled trial}

R G Watt, K I Tull, R Hardy, M Wiggins, Y Kelly, B Molloy, E Dowler, J Apps and P McGlone

J Epidemiol Community Health 2009;63;156-162

doi:10.1136/jech.2008.077115

Updated information and services can be found at:

http://jech.bmj.com/cgi/content/full/63/2/156

These include:

References This article cites 17 articles, 8 of which can be accessed free at:

http://jech.bmj.com/cgi/content/full/63/2/156\#BIBL

Rapid responses You can respond to this article at:

http://jech.bmj.com/cgi/eletter-submit/63/2/156

Email alerting Receive free email alerts when new articles cite this article - sign up in the box at service the top right corner of the article

Notes

To order reprints of this article go to:

http://journals.bmj.com/cgi/reprintform

To subscribe to Journal of Epidemiology and Community Health go to:

http:/journals.bmj.com/subscriptions/ 


\title{
Effectiveness of a social support intervention on infant feeding practices: randomised controlled trial
}

\author{
R G Watt, ${ }^{1} \mathrm{~K}$ I Tull, ${ }^{1} \mathrm{R}$ Hardy, ${ }^{1}$ M Wiggins, ${ }^{2}$ Y Kelly, ${ }^{1}$ B Molloy, ${ }^{3}$ E Dowler, ${ }^{4} \mathrm{~J}$ Apps, ${ }^{5}$ \\ P McGlone ${ }^{6}$
}

${ }^{1}$ Department of Epidemiology and Public Health, University College London, London, UK;

${ }^{2}$ Social Science Research Unit, Institute of Education, University of London, London, UK;

${ }^{3}$ Community Mothers

Programme, Health Service

Executive, Dublin, Ireland;

${ }^{4}$ Department of Sociology,

University of Warwick, Coventry;

${ }^{5}$ Research and Policy, National

Family and Parenting Institute,

London, UK; ${ }^{6}$ Primary Care

Research Network, Peninsula

Medical School, Royal Cornwall

Hospital, Cornwall, UK

Correspondence to:

Professor R G Watt, Department of Epidemiology and Public

Health, UCL, 1-19 Torrington

Place, London WC1E 6BT, UK;

r.watt@ucl.ac.uk

Accepted 29 September 2008

\begin{abstract}
Background: To assess whether monthly home visits from trained volunteers could improve infant feeding practices at age 12 months, a randomised controlled trial was carried out in two disadvantaged inner city London boroughs.
\end{abstract}

Methods: Women attending baby clinics with their infants (312) were randomised to receive monthly home visits from trained volunteers over a 9-month period (intervention group) or standard professional care only (control group). The primary outcome was vitamin C intakes from fruit. Secondary outcomes included selected macro and micro-nutrients, infant feeding habits, supine length and weight. Data were collected at baseline when infants were aged approximately 10 weeks, and subsequently when the child was 12 and 18 months old.

Results: Two-hundred and twelve women (68\%) completed the trial. At both follow-up points no significant differences were found between the groups for vitamin C intakes from fruit or other nutrients. At first follow-up, however, infants in the intervention group were significantly less likely to be given goats' or soya milks, and were more likely to have three solid meals per day. At the second follow-up, intervention group children were significantly less likely to be still using a bottle. At both follow-up points, intervention group children also consumed significantly more specific fruit and vegetables.

Conclusions: Home visits from trained volunteers had no significant effect on nutrient intakes but did promote some other recommended infant feeding practices.

Trial registration: Current Controlled Trials ISRCTN55500035

Nutrition in early life is a key determinant of growth, development and health status, both in childhood and later adult life. ${ }^{12}$ Current UK recommendations advise all mothers to exclusively breastfeed for 6 months, and to delay introducing solids until at least 6 months. ${ }^{3-5}$ Data from national surveys show that infant feeding practices in the UK are, however, highly variable. ${ }^{67}$ The 2005 Infant Feeding Survey indicated some encouraging trends with $76 \%$ of mothers across the UK initiating breastfeeding. However, rates fell steeply after a few weeks and less than $1 \%$ of mothers were exclusively breastfeeding at 6 months. ${ }^{6}$ Stark social inequalities were evident, with breastfeeding rates highest amongst older, middle-class and educated mothers. The 2005 survey also reported that $51 \%$ of mothers had introduced solids by 4 months and only $2 \%$ had delayed introducing solids until 6 months. Mothers giving solids when babies were 4-6 months were more likely to provide commercially prepared foods $(85 \%)$ than home prepared (51\%), and only $46 \%$ had given fruit. ${ }^{6}$

A substantial body of research has evaluated interventions aimed at increasing the initiation, and to lesser extent, the duration of breastfeeding. ${ }^{89}$ In contrast, very few well-designed studies have evaluated interventions focusing on the later stages of infant feeding beyond breastfeeding. ${ }^{10}$ Recent National Institute of Health and Clinical Excellence (NICE) guidance has highlighted the paucity of studies on complementary (weaning) feeding practices. ${ }^{5}$ A small randomised trial evaluated the effect of a prenatal nutrition education intervention targeted at Asian women in east London. When the children were 1 year old, no effect was found on biochemical indices of their nutrient status. ${ }^{11}$ A larger US randomised trial successfully delayed the first introduction of solid foods through the provision of postnatal breastfeeding counselling, and by changing the contents of hospital discharge packs. ${ }^{12}$ A Finnish randomised trial assessed the effect of intensive individual dietary counselling on infants' fat consumption. ${ }^{13}$ The intervention had no effect on growth or daily energy intake, but did lower the percentage energy from fat, cholesterol levels and the polyunsaturated/saturated fat ratio. Two other trials in the midlands and north of England evaluated the effect of weaning advice from health visitors on increasing iron-rich foods and vitamin $\mathrm{C}$ to prevent anaemia in samples of lower income ethnic minority women. ${ }^{14}{ }^{15}$ Neither study reported significant differences between intervention and control groups in the range of outcomes assessed. A non-randomised study in the north-east of England showed that participant-centred health education increased the use of home-cooked foods in a sample of mothers with infants aged 7 9 months. ${ }^{16}$ Encouraging results have been achieved through a social support intervention. An Irish randomised trial examined the effectiveness of monthly home visits during the first year of a child's life by non-professional community mothers. ${ }^{17}$ The intervention focused on developing general parenting skills in a sample of first-time mothers living in a deprived area of Dublin. Significant nutritional, health and educational benefits were demonstrated at post intervention. A 7-year follow-up showed that the programme had sustained beneficial effects on parenting skills and maternal self-esteem. ${ }^{18}$

Based on the approach adopted in the Community Mothers Programme ${ }^{17}$ and the evidence of the effectiveness of peer support on breastfeeding practices, ${ }^{8}$ we developed a social 
support intervention specifically designed to promote recommended infant feeding practices in a sample of mothers living in a disadvantaged inner city area. The aim was to ascertain whether monthly home visits from trained volunteers could improve infant feeding practices and, in particular, increase infants daily vitamin $\mathrm{C}$ intakes from fruit consumption at 12 months in a lower income sample.

\section{METHODS}

\section{Participants}

The study was conducted in the inner London boroughs of Camden and Islington, the fifteenth and fourth most deprived boroughs, respectively, in the UK. ${ }^{19}$ Women were recruited from December 2002 to February 2004 at baby clinics located in the more disadvantaged neighbourhoods across Camden and Islington where Surestart (a national social welfare initiative targeting families with young children) programmes existed. ${ }^{20} \mathrm{~A}$ standardised technique was used to approach new mothers attending the baby clinics. An overview of the study was given and randomisation explained. If the women were interested, a short screening questionnaire was then used to assess their eligibility. The inclusion criteria for the study included: women from Registrar General occupational classes II-V (non-professional); babies born $\geqslant 37$ weeks; babies' birth weight above $2500 \mathrm{~g}$; singletons; women able to understand written and spoken English; and resident in the study area. Participants were excluded if: women were under 17 years old; infants were diagnosed with a serious medical condition or were on special diets; infants were aged over 12 weeks; women or their partners were from social class I (professional). Originally, the intention was to restrict the sample to first-time mothers only. However, major difficulties were encountered in recruiting sufficient numbers of first-time mothers over the initial 12 weeks of the recruitment period. The inclusion criteria was therefore changed to include all new mothers. Eligible women were subsequently contacted and arrangements agreed for a researcher to attend to gain consent and gather baseline data.

Women recruited were then randomly allocated to the intervention or control groups. A random allocation schedule was prepared in advance using random digit computer tables. Following recruitment, women were allocated a sequential identification number and simple randomisation was used to allocate them to either intervention or control group. The study administrator was responsible for the randomisation process. As a result, those responsible for recruiting and assessing outcomes were all masked to group assignment. Ethical approval for the study was granted by the Local Research Committee of the Camden and Islington Community Health Services NHS Trust. All participants provided written informed consent.

\section{Intervention}

The intervention was based upon a social support theoretical model $^{21}$ and consisted of the offer of practical and nonjudgemental support and advice on infant feeding practices, in particular complementary feeding, provided by trained volunteers. The intervention adopted a holistic approach to infant nutrition and was designed to empower the women to follow current guidance on the later stages of infant feeding practices, in particular when to introduce solids, the types of foods and drinks to give a child with emphasis on the importance of fruit and vegetables, and when to stop using a feeding bottle. ${ }^{34} \mathrm{~A}$ group of local mothers were recruited and trained to provide the support in a 12-session programme delivered over a 4-week period. ${ }^{22}$ Once trained and relevant police and safety checks undertaken, the volunteers were matched to women in the intervention group. Monthly home visits were then offered from when the baby was about 3 months old until their first birthday. Volunteers were encouraged to provide very practical support and to offer a listening ear to the mother's concerns and worries about infant feeding. The support offered by the volunteers was designed to complement the advice and support offered by health professionals. Women in the control group only received standard professional support from health visitors and GPs.

\section{Outcome measures}

The primary outcome measure was vitamin C from fruit at 12 months. This was selected as fruit consumption is very low amongst young children and marked inequalities are found. ${ }^{5} 23$ The secondary outcomes were: selected macro and micronutrients; infant feeding habits; fruit and vegetable consumption; and supine length and weight. In addition, the mother's consumption of fruit and vegetables, and nutritional knowledge and confidence were also assessed.

The primary outcome, daily vitamin $\mathrm{C}$ intake from fruit, was used to determine the sample size. Data from the National Diet and Nutrition Survey ${ }^{23}$ showed that at 18 months, children from manual households consumed $6.2 \mathrm{mg}$ vitamin C from fruit. It was predicted that the intervention group would increase their vitamin $\mathrm{C}$ intake from fruit to $12.6 \mathrm{mg}$ (SD 11.6), equivalent to two additional pieces of fruit being consumed each day. To have a $90 \%$ chance of detecting this $6.4 \mathrm{mg}$ difference at a 0.05 level of significance, 87 participants were needed in the intervention and control groups at final followup. ${ }^{24}$ Based upon a predicted $40 \%$ loss to final follow-up, it was estimated that, in total, 318 participants would be required.

Data were collected at baseline when the infants were 10 weeks old, and at two subsequent follow-ups when the children were aged 12 and 18 months respectively. The 24-hour multiple pass recall method was used to collect nutritional data. This is a very detailed and systematic method to assess nutritional intakes. The validity, reliability and acceptability of this method has been demonstrated in a low income population, ${ }^{25}$ and the method was used in the recently published Low Income Diet and Nutrition Survey. ${ }^{26}$ Interviews with mothers were used to collect the other outcome data. The children's weight was measured using calibrated Soehnle quantratonic scales and supine length was measured with a portable rollameter. In addition, a validated 14-item food frequency questionnaire was used to assess the mothers' consumption of fruit and vegetables. ${ }^{27}$ An extensive quality assurance system was instigated to ensure the data quality throughout the duration of the study.

\section{Statistical analysis}

Analysis was carried out on an intention to treat basis. At both follow-ups outcomes were compared between the intervention and control groups. For the continuous outcomes the two groups were compared by two-sample t-tests. Where continuous variables exhibited non-normal distributions, the $p$ value from the Mann-Whitney U-test was also calculated. Mean differences (treatment mean - control mean) with 95\% confidence intervals (CI) are quoted. For categorical data, $\chi^{2}$ tests and, where the number in at least one cell of the $2 \times 2$ table was small (less than five cases), Fisher's Exact test, were used. The results were expressed as relative risks (RR) with 95\% CI. 
The $\mathrm{p}$ values are two-sided and statistical significance was defined at the 5\% level. Analyses were carried out using SPSS (version 13).

\section{RESULTS}

In total, 312 women were recruited into the study from December 2002 to February 2004. This represented $82 \%$ of the 381 women who were approached and deemed eligible for participation in the study (figure 1). Those women who were eligible, but declined, were similar in terms of their age, parity, education and social class to women who participated in the study. The main reasons for declining were women being too busy, experiencing health problems, or they expressed a lack of willingness to accept volunteer home visits. Sixty-two per cent of the sample were firsttime mothers and $50 \%$ described themselves as being from an ethnic minority group. The mean age of mothers at the birth of the index child was 30 years. The infants' mean age was 10 weeks. Overall, the sample was relatively disadvantaged with $28 \%$ being lone parents, $57 \%$ living in social housing and $33 \%$ receiving income support/jobseekers allowance. The women in both intervention and control groups were similar in terms of baseline socio-demographic, infant feeding and nutritional variables (table 1). Overall, response rates at the two follow-up points were $77 \%$ and $68 \%$, and this was evenly balanced for the intervention and control groups.

Twenty-seven volunteers successfully completed their training and were matched with women in the intervention group. The matching process required careful consideration of the needs and circumstances of both parties. Home-based support was offered over a 9-month period until the infants were 12 months old. In total, 758 home visits were made, and the mean length of each visit was 60 minutes, excluding travel time. On average each woman in the intervention group received five volunteer home visits (range one to ten). A small number of women were also contacted by telephone when home visits were not possible.

At the first follow-up, 239 women (77\%) were interviewed and the mean age of the child was 12 months and 3 weeks. No significant difference was found between the intervention and control groups for the primary outcome, vitamin C from fruit, where the estimated mean difference was $-1.4 \mathrm{mg}(95 \% \mathrm{CI}$ -6.6 to $3.8, p=0.59)$. The Mann-Whitney test was also nonsignificant $(p=0.9)$. There were no significant differences for the other macro- and micro-nutrients assessed (table 2). When infants taking nutritional supplements or who were sick during the data collection period were excluded in the nutritional analysis, again no differences were found. Infants in the intervention group were $0.4 \mathrm{~kg}$ (95\% CI 0.1 to 0.7$)$ heavier than those in the control group $(p=0.05)$. No significant differences were found in the duration of exclusive breastfeeding between the groups or the timing of the introduction of solid foods (table 3). However, significant differences were found in relation to certain feeding practices. Infants in the intervention group were significantly less likely to be given goats' or soya milks and were more likely to be eating three solid meals per day compared to infants in the control group. Infants in the intervention group were also $10 \%$ more likely to consume apples more than once a week, $40 \%$ more likely to consume pears, $20 \%$ more likely to consume boiled potatoes, and $10 \%$ more likely to consume carrots than those in the control group. The intervention did not have any significant effect on the mother's consumption of fruit and vegetables, or their nutritional knowledge and confidence in following recommendations on how to feed their babies (table 3 ).

At the final follow-up, 212 women (68\%) were interviewed and the mean age of the child was 18 months and 2 weeks. No significant differences were found for vitamin $\mathrm{C}$ from fruit, where the estimated mean difference was $-1.5 \mathrm{~g}$ (95\% CI -6.5
Figure 1 CONSORT flow chart of participants.

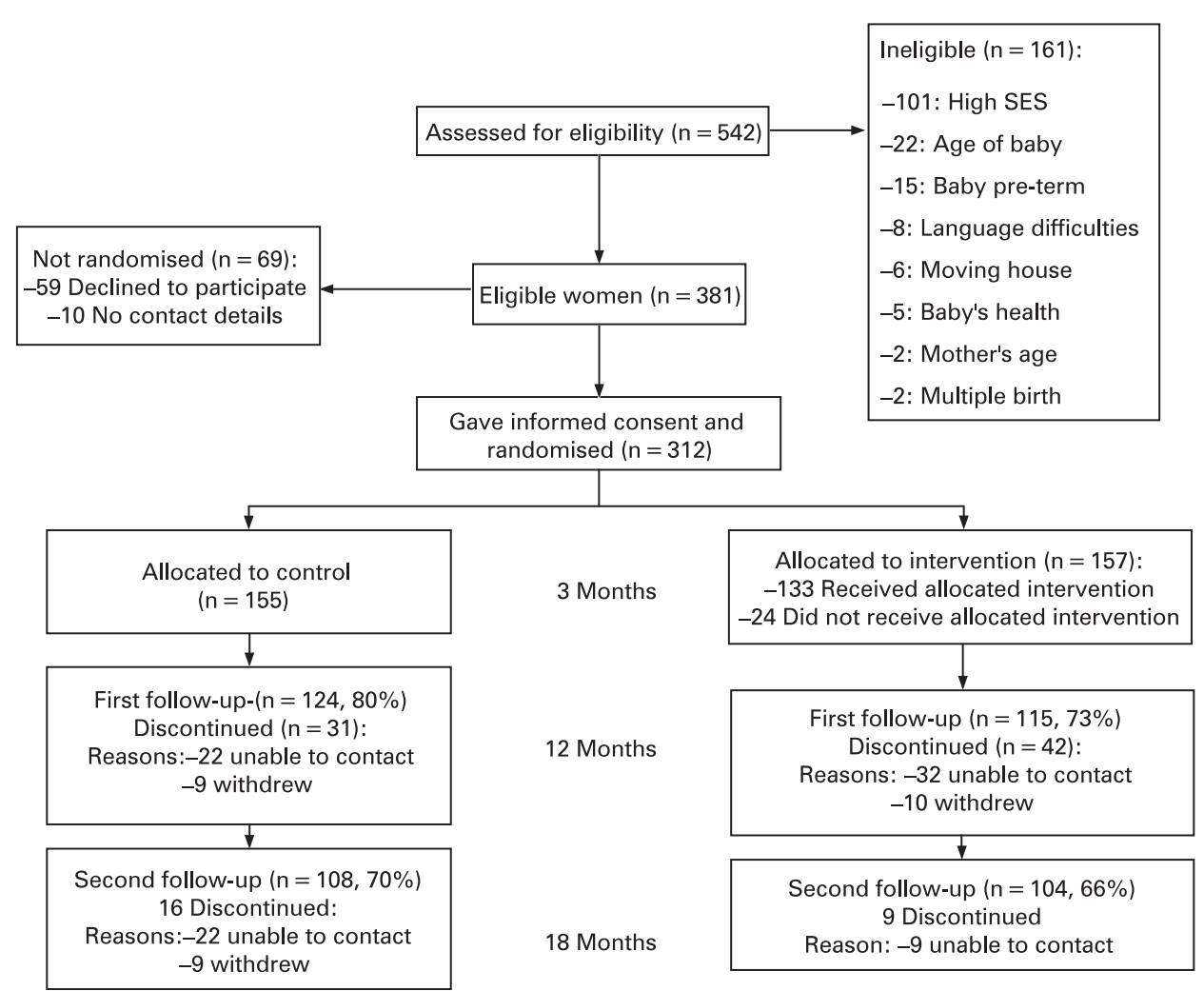


Table 1 Baseline characteristics of sample by trial arm

\begin{tabular}{lcc}
\hline & Intervention (n=157) & Control (n=155) \\
\hline First baby & $98(62)$ & $94(61)$ \\
Ethnicity: white & $79(50)$ & $77(50)$ \\
Lone parent & $47(30)$ & $39(25)$ \\
Mother's age at birth of index child (years) mean (SD) & $29.3(6)$ & $31(6.2)$ \\
Infant's age at baseline (weeks) mean (SD) & $10(2)$ & $10.2(2.3)$ \\
Household receives income support/jobseekers allowance & $52(33)$ & $51(33)$ \\
Mother left full time education $<16$ years & $39(25)$ & $33(21)$ \\
Social housing & $95(60)$ & $83(54)$ \\
Exclusive breastfeeding & $62(39)$ & $71(46)$ \\
Problems with feeding since birth & $74(47)$ & $81(53)$ \\
Energy (kcal) mean (SD) & $712.9(205.5)$ & $688.7(187.6)$ \\
Protein (g) mean (SD) & $14.3(3.7)$ & $13.7(3.2)$ \\
Fat (g) mean (SD) & $40.7(13)$ & $39.4(11.8)$ \\
Carbohydrate (g) mean (SD) & $75.9(21)$ & $73.1(19)$ \\
Vitamin C (mg) mean (SD) & $59(19)$ & $56(16.7)$ \\
Infants mean weight mean (kg) (SD) & $5.5(0.7)$ & $5.5(0.7)$ \\
Infants supine mean length mean (cm) (SD) & $60.1(2.8)$ & $60.1(2.6)$ \\
Mothers consumption of five or more portions of fruit/veg. per day & $68(43)$ & $66(43)$ \\
\hline
\end{tabular}

Values are numbers (percentages) unless stated otherwise.

to $3.6 \mathrm{p}=0.56$ ). There were no significant differences for other macro- and micro-nutrients assessed (table 4). The weights and heights were also similar between intervention and control groups. Certain feeding practices were, however, significantly different. Children in the intervention group (57\%) were significantly less likely to be still using a bottle than those in the control group (74\%) (table 5). No significant differences were found in terms of their consumption of cows milk or squash (cordial) drinks. However, children in the intervention group were $30 \%$ more likely to consume pears more than once a week, 10\% more likely to consume potatoes and $60 \%$ more likely to consume chips than those in the control group. Significant positive differences were seen for mothers' nutritional knowledge on when bottle use should be discouraged, but there was no effect on the mothers' consumption of fruit and vegetables.

\section{DISCUSSION}

In this study conducted with a relatively disadvantaged sample, it has been shown that home visits by trained volunteers had no significant effect on vitamin $\mathrm{C}$ intakes and other macro- and micro-nutrients between the intervention and control groups at either follow-up. The intervention did, however, have an effect on other feeding practices. At the first follow-up when the infant was 12 months old, mothers who had been visited by a volunteer were more likely to give their child certain fruits and vegetables, and were less likely to give goats' or soya milk. Infants in the intervention group were also more likely to be having three solid meals each day. At the final follow-up, children in the intervention group were still consuming more of certain items of fruit and vegetables, and were less likely to be still using a bottle. These practices are all broadly in line with current infant feeding recommendations. ${ }^{45}$ The intervention group did, however, increase their consumption of chips, which may have been due to some confusion over whether chips were considered a vegetable. The intervention did not, however, have any significant effect on the duration of breastfeeding, or the timing of introducing solid foods.

Findings from systematic reviews indicate that social support has a beneficial effect in promoting the duration of exclusive breastfeeding. ${ }^{78}$ Social support interventions have also

Table 2 Nutritional and anthropometric outcomes at first follow-up (child 12 months old)

\begin{tabular}{|c|c|c|c|c|c|c|c|c|}
\hline & \multicolumn{3}{|c|}{ Intervention } & \multicolumn{3}{|c|}{ Control } & \multirow{2}{*}{$\begin{array}{l}\text { Difference in means } \\
95 \% \mathrm{CI}\end{array}$} & \multirow[b]{2}{*}{ p Value } \\
\hline & $\mathbf{N}$ & Mean & SD & $\mathbf{N}$ & Mean & SD & & \\
\hline Vitamin C from all fruit (mg) & 115 & 17.2 & 18.3 & 123 & 18.6 & 22.1 & $-1.4(-6.6$ to 3.8$)$ & $0.59^{*}$ \\
\hline Energy (kcal) & 115 & 1028 & 303 & 123 & 1008 & 276 & $20(-54$ to 94$)$ & 0.60 \\
\hline Protein $(\mathrm{g})$ & 115 & 39.5 & 14.2 & 123 & 37.7 & 13 & $1.8(-1.7$ to 5.3$)$ & 0.31 \\
\hline Fat $(\mathrm{g})$ & 115 & 43.9 & 14.2 & 123 & 42.7 & 14.3 & $1.2(-2.4$ to 4.8$)$ & 0.51 \\
\hline Carbohydrate $(\mathrm{g})$ & 115 & 129.8 & 40.7 & 123 & 126.4 & 35.9 & $3.4(6.5$ to 13.2$)$ & 0.50 \\
\hline Total sugars $(\mathrm{g})$ & 115 & 69.0 & 28.2 & 123 & 67.2 & 24.6 & $1.8(-5.0$ to 8.6$)$ & 0.60 \\
\hline NMES $\uparrow(g)$ & 115 & 17.8 & 18.8 & 123 & 16.9 & 13.9 & $0.8(-3.5$ to 5.0$)$ & 0.70 \\
\hline Calcium (mg) & 115 & 844 & 370 & 123 & 813 & 317 & $31(-57$ to 119$)$ & 0.48 \\
\hline Iron (mg) & 115 & 7.7 & 3.7 & 123 & 7.9 & 4.5 & $-0.2(-1.2$ to 0.9$)$ & 0.72 \\
\hline Vitamin A $(\mu \mathrm{g})$ & 115 & 747 & 290 & 123 & 814 & 474 & $-66(-166$ to 33$)$ & 0.19 \\
\hline Vitamin $D(\mu \mathrm{g})$ & 115 & 3.0 & 3.4 & 123 & 3.5 & 3.3 & $-0.5(-1.3$ to 0.4$)$ & 0.27 \\
\hline Vitamin E (mg) & 115 & 4.4 & 2.5 & 123 & 4.6 & 2.1 & $-0.1(-0.7$ to 0.5$)$ & 0.67 \\
\hline Weight (kg) & 110 & 10.3 & 1.2 & 121 & 9.9 & 1.15 & $0.4(0.1$ to 0.7$)$ & 0.05 \\
\hline Length $(\mathrm{cm})$ & 110 & 78.4 & 3.0 & 120 & 77.8 & 2.89 & $0.66(-0.1$ to 1.4$)$ & 0.16 \\
\hline
\end{tabular}

\footnotetext{
*Mann-Whitney test: $p=0.9$
}

†Non-milk extrinsic sugars 
Table 3 Feeding practices and mothers' outcomes at first follow-up (child 12 months old)

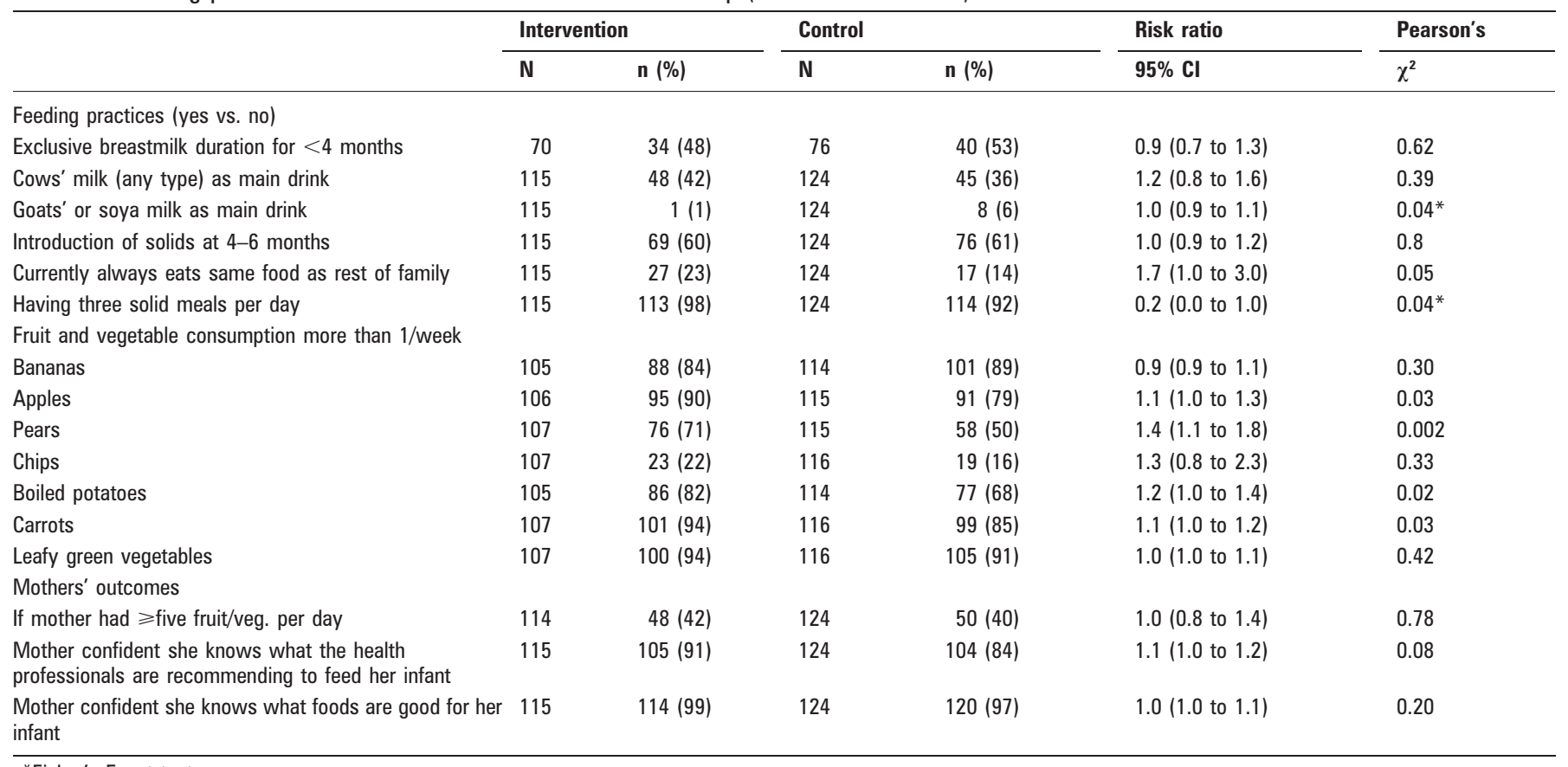

*Fisher's Exact test.

demonstrated positive findings in relation to increasing fruit and vegetable consumption amongst socially disadvantaged adult populations in the US. ${ }^{28}{ }^{29}$ Few high-quality studies have gone beyond breastfeeding onto the complementary and more established feeding periods, and the overall results have been disappointing. ${ }^{5}{ }^{10}$ Interventions delivered by health professionals have had limited effect on later infant feeding practices, especially amongst socially disadvantaged women. ${ }^{11-16}$ This well-designed study, however, with a social support intervention targeting lower income mothers did have a significant influence on a range of infant feeding outcomes. For example, increasing consumption of fruits and vegetables, eating family meals and stopping the use of bottles at the 18-month stage are all positive outcomes with important potential longer term health and developmental benefits. Experimental studies with infants and young children have shown that exposure to foods affects their acceptability and consumption. ${ }^{30}{ }^{31}$ This intervention had no effect on vitamin $\mathrm{C}$ intake, the primary outcome, or other nutrients. However, at each stage of the trial nutrient intakes for both the intervention and control groups were in line with Reference Nutrient Intakes (RNI). It is not surprising that the intervention failed to have any effect on the duration of breastfeeding as the home visits only started when the child was 3 months old, by which time decisions on breastfeeding had already been made. However, it was disappointing that the timing of introducing solid foods was not influenced by the intervention as this was one of the main issues discussed at the home visits. Other studies have shown that weaning practices are 'baby-led', in that the mother's decision on when to introduce solids is largely determined by the infant's physical characteristics and behavioural actions, and indeed may be in conflict with health professionals' advice. ${ }^{32} 33$

The strengths of this study are the randomised design, the allocation was well concealed and an intention to treat analysis

Table 4 Nutritional and anthropometric outcomes at final follow-up (child 18 months old)

\begin{tabular}{|c|c|c|c|c|c|c|c|c|}
\hline & \multicolumn{3}{|c|}{ Intervention } & \multicolumn{3}{|c|}{ Control } & \multirow{2}{*}{$\begin{array}{l}\text { Difference in means } \\
95 \% \mathrm{Cl}\end{array}$} & \multirow[b]{2}{*}{ p Value } \\
\hline & $\mathbf{N}$ & Mean & SD & $\mathbf{N}$ & Mean & SD & & \\
\hline Vitamin C from all fruit (mg) & 104 & 19.9 & 19.3 & 108 & 21.4 & 18.0 & $-1.5(-6.5$ to 3.6$)$ & $0.56^{*}$ \\
\hline Energy (kcal) & 104 & 1175 & 282 & 108 & 1202 & 324 & $-27.7(-19.8$ to 54.4$)$ & 0.50 \\
\hline Protein $(\mathrm{g})$ & 104 & 45.7 & 13.6 & 108 & 44.6 & 12.1 & $1.2(-2.3$ to 4.7$)$ & 0.50 \\
\hline Fat $(\mathrm{g})$ & 104 & 47.2 & 13.6 & 108 & 48.1 & 13.8 & $-0.9(-4.6$ to 2.8$)$ & 0.62 \\
\hline Carbohydrate $(\mathrm{g})$ & 104 & 151.5 & 47.3 & 108 & 156.8 & 61.1 & $-5.2(-20$ to 9.5$)$ & 0.48 \\
\hline Total sugars $(\mathrm{g})$ & 104 & 85.0 & 40.5 & 108 & 89.8 & 51.9 & $-4.8(-17.4$ to 7.8$)$ & 0.45 \\
\hline NMES $\uparrow(g)$ & 104 & 34.9 & 49.2 & 108 & 37.0 & 49.5 & $-2.7(-16$ to 10.7$)$ & 0.33 \\
\hline Calcium (mg) & 104 & 883 & 359 & 108 & 888 & 294 & $-6(-94$ to 84$)$ & 0.90 \\
\hline Iron (mg) & 104 & 6.8 & 2.8 & 108 & 7.9 & 5.4 & $-1.1(-2.3$ to 0.1$)$ & 0.06 \\
\hline Vitamin A $(\mu \mathrm{g})$ & 104 & 641 & 246 & 108 & 694 & 453 & $-52(-152$ to 46$)$ & 0.29 \\
\hline Vitamin D $(\mu \mathrm{g})$ & 104 & 1.8 & 2.6 & 108 & 1.9 & 2.9 & $-0.1(-0.9$ to 0.6$)$ & 0.72 \\
\hline Vitamin E (mg) & 104 & 4.0 & 1.9 & 108 & 4.0 & 2.0 & $0.0(-0.6$ to 0.5$)$ & 0.93 \\
\hline Weight $(\mathrm{kg})$ & 103 & 11.6 & 1.3 & 108 & 11.3 & 1.4 & $0.3(-0.1$ to 0.6$)$ & 0.12 \\
\hline Length $(\mathrm{cm})$ & 103 & 84.2 & 3.3 & 108 & 84 & 3.5 & $0.2(-0.7$ to 1.1$)$ & 0.67 \\
\hline
\end{tabular}

\footnotetext{
*Mann-Whitney test: $p=0.36$.
}

†Non-milk extrinsic sugars. 
Table 5 Feeding practices and mothers' outcomes at final follow-up (child 18 months old)

\begin{tabular}{|c|c|c|c|c|c|c|}
\hline & \multicolumn{2}{|c|}{ Intervention } & \multicolumn{2}{|c|}{ Control } & \multirow{2}{*}{$\begin{array}{l}\text { Risk ratio } \\
95 \% \mathrm{CI}\end{array}$} & \multirow{2}{*}{$\begin{array}{l}\text { Pearson's } \\
\chi^{2}\end{array}$} \\
\hline & $\mathbf{N}$ & n $(\%)$ & $\mathbf{N}$ & n $(\%)$ & & \\
\hline \multicolumn{7}{|l|}{ Feeding practices (yes vs. no) } \\
\hline Cows' milk (full-fat) as main drink & 104 & $65(63)$ & 108 & $67(62)$ & $1.1(0.8$ to 1.2$)$ & 0.95 \\
\hline Does not drink squash (Ribena) or other cordial drinks & 104 & $25(24)$ & 108 & $33(31)$ & $0.8(0.6$ to 1.2$)$ & 0.29 \\
\hline No longer using a bottle & 104 & $43(41)$ & 108 & $26(24)$ & $1.7(1.2$ to 2.6$)$ & 0.007 \\
\hline \multicolumn{7}{|l|}{ Fruit and vegetable consumption more than $1 /$ week } \\
\hline Bananas & 102 & $91(89)$ & 104 & $97(93)$ & $1.0(0.9$ to 1.0$)$ & 0.30 \\
\hline Pears & 103 & $66(64)$ & 105 & $52(50)$ & $1.3(1.0$ to 1.7$)$ & 0.03 \\
\hline Chips & 103 & $37(36)$ & 105 & $23(22)$ & $1.6(1.1$ to 2.6$)$ & 0.03 \\
\hline Other potatoes & 103 & $94(91)$ & 105 & $86(82)$ & $1.1(1.0$ to 1.2$)$ & 0.04 \\
\hline Carrots & 103 & $88(85)$ & 105 & $84(80)$ & $1.1(0.9$ to 1.2$)$ & 0.30 \\
\hline Leafy green vegetables & 103 & $91(88)$ & 105 & $86(82)$ & 1.1 (1.0 to 1.2 ) & 0.19 \\
\hline \multicolumn{7}{|l|}{ Mothers' outcomes } \\
\hline
\end{tabular}

was carried out. Also, refusal to participate and loss to followups were acceptable providing sufficient numbers to achieve the power to show differences in this trial. The recruitment, training and retention of volunteers meant that the social support offered to women was successfully implemented. A separate process evaluation indicated a high level of satisfaction from the women who received the home visits. ${ }^{34}$ Inevitably, the study had certain weaknesses. Originally, the study intended to only recruit first-time mothers who were considered most likely to benefit from the planned intervention. However, problems were encountered in recruiting sufficient numbers of eligible women. As such, the inclusion criteria were modified to include all new mothers. In the end, $62 \%$ of the women recruited were first-time mothers. Also, although attempts were made to recruit younger women, the mean age of those recruited was 30 years. If the sample had consisted of a higher proportion of younger, first-time mothers, the impact of the intervention may have been greater. Evidence indicates that social support interventions are most effective when the volunteers and those they are supporting are similar in background. ${ }^{21}$ Although all the volunteers were local women and mothers themselves from a similar social background to the women they visited, the volunteers were on average 6 years older. Attempts were made to recruit younger volunteers but this was not successful, possibly due to the level of commitment required. The intervention consisted of monthly home visits, or when this was not possible, telephone contact was made. Feedback from participants indicated that the offer of group support and a more flexible style of approach would have been welcomed. ${ }^{34}$ For example, women may have benefited more, if more frequent visits had been offered at important periods when particular weaning problems were occurring. Finally, the women recruited into the trial although from a broadly disadvantaged background may not be representative of the general population. At baseline, a higher proportion of the women recruited were still breastfeeding compared to UK national average and vitamin C intakes were also higher than expected at both follow-ups. However, very few high-quality and up to date data exist on nutrient intakes on infants and young children, making it difficult to compare our nutrient results with any 'gold standard'. The sample recruited may have been more interested and committed to following infant feeding recommendations than the general population. This would certainly reduce the potential impact of the intervention as the control group would be already highly motivated and enthusiastic about infant feeding. The generalisability of our findings may also be affected by the selective nature of the study sample.

Infant feeding practices have a major impact on the development, growth and health status of young children. It has been shown that the provision of non-judgemental and practical support from trained volunteers has achieved a range of positive feeding outcomes in a socially disadvantaged sample. Social support interventions that focus on feeding practices may therefore have an important role in reducing inequalities in child health. Further research is needed to determine whether different models of social support might provide greater impact on infant feeding practices, for example individual versus group support; timing of when to commence visits; home visits versus telephone support; and frequency of visits. Additionally, social support alone may be insufficient to tackle the wide range of factors that influence infant feeding practices. We recommend that further work is needed to assess how a social support

\section{What is already known on this subject}

- Nutrition in early life is an important determinant of health, both in childhood and later adult life.

- Stark inequalities exist in infant feeding practices in the UK.

- Few well-designed interventions have focused on later stages of infant feeding beyond breastfeeding.

\section{What this study adds}

- This social support intervention targeting lower income mothers failed to increase vitamin $\mathrm{C}$ intakes in children aged 12 and 18 months.

- The intervention did, however, have a significant effect on other important feeding practices. 
intervention could be embedded within a multifaceted strategy that aims to address the broader determinants of infant feeding.

Acknowledgements: We are very grateful to all the women who participated in the trial and to the volunteers who demonstrated great commitment and enthusiasm. We would also like to thank the members of the study steering group for their assistance and support.

Funding: This study was supported by the UK Food Standards Agency (N09016).

Competing interests: None.

Ethics approval: Local Research Committee of the Camden and Islington Community Health Services NHS Trust.

\section{REFERENCES}

1. World Health Organization. Diet, nutrition and the prevention of chronic diseases. Report of a joint WHO/FAO expert consultation. Geneva: World Health Organization, 2003.

2. Fall CHD, Barker DJP, Osmond C, et al. Relation of infant feeding to adult serum cholesterol concentration and death from ischaemic heart disease. $\mathrm{Br}$ Med $J$ 1992;304:801-05.

3. Department of Health. Weaning and the weaning diet. Report on Health and Social Subjects. Report of the Working Group on the weaning diet of the committee on medical aspects of food policy. London: HMSO, 1994.

4. Department of Health. Infant feeding recommendations. London: Department of Health, 2003.

5. National Institute for Health and Clinical Excellence (NICE). Maternal and Child Nutrition. Public health guidance 11. London: NICE, 2008.

6. Bolling K, Grant C, Hamlyn B, et al. Infant feeding survey 2005. London: Information Centre, 2007.

7. Kelly Y, Watt RG. Breastfeeding initiation and exclusive duration at 6 months by social class - results from the Millennium Cohort Study. Public Health Nutr 2005:8:417-421.

8. Dyson L, McCormick F, Renfrew MJ. Interventions for promoting the initiation of breastfeeding. (Cochrane Review). In the Cochrane Library (Issue 4). Oxford: Update Software, 2005.

9. Sikorski J, Renfrew MJ, Pindoria S, et al. Support for breastfeeding mothers. (Cochrane Review). In The Cochrane Library (Issue 2). Oxford: Update Software, 2004.

10. Tedstone A, Dunce N, Aviles M, et al. Effectiveness of interventions to promote healthy feeding in infants under one year of age: a review. London: Health Education Authority, 1998.

11. McEnery G, Rao K. The effectiveness of antenatal education of Pakistani and Indian women living in this country. Child Care Health Dev 1986;12:385-399.

12. Frank D, Wirtz SJ, Sorenson JR, et al. Commercial discharge packs and breast feeding counselling: effects on infant feeding practices in a randomized trial. Paediatrics 1987:80:845-854.

13. Lapinleimu H, Viikari J, Jokinen E, et al. Prospective randomized trial in 1062 infants of diet low in saturated fat and cholesterol. Lancet 1995;345:471-476.
14. Griffiths $\mathbf{B}$, et al. Health education and iron intakes of weaning children. Health Visit 1995;68:418-419.

15. Childs F, Aukett A, Darbyshire P, et al. Dietary education and iron deficiency anaemia in the inner city. Arch Dis Child 1997;76:1447.

16. Hoare $\mathbf{K}$, Wright $\mathrm{CM}$, Wilson $\mathrm{P}$, et al. Disseminating weaning messages: an intervention trial. Br J Community Nurs 2002;7:196-200.

17. Johnson Z, Howell F, Molloy B. Community mothers programme: randomised controlled trial of a non-professional intervention in parenting. Br Med $\mathrm{J}$ 1993;306:1449-1452.

18. Johnson Z, Molloy B, Scallan E, et al. Community mothers programme - seven year follow-up of a randomised controlled trial of non-professional intervention in parenting. J Public Health Med 2000;22:337-342.

19. Noble M, et al. English Indices of Deprivation, revised, 2004. Report to the Office of the Deputy Prime Minister. London: Neighbourhood Renewal Unit, 2004.

20. Department of Education and Employment. Sure Start: Making a difference for children and families. London: Department of Education and Employment, 1999.

21. Cohen S, McKay G. Social support, stress and the buffering hypothesis, a theoretical analysis. In: Baum A, Singer J, Taylor S, eds. Handbook of Psychology and Health. Hillside NJ: Laurence Erlbaum, 1984:253-67.

22. Watt RG, McGlone P, Russell J, et al. The process of establishing, implementing and maintaining a social support infant feeding programme. Public Health Nutr 2006;9:714-721.

23. Gregory JR, Collins DL, Davies PS, et al. National diet and nutrition survey: children aged 1.5 to 4.5 years. Vol 1. Report of the diet and nutrition survey. London: HMSO, 1995.

24. Kirkwood BR, Sterne JA. Essential Medical Statistics (second edition). Oxford: Blackwell Publishing, 2003.

25. Nelson M, Dick K, Holmes B, et al. Low Income Diet Methods Study. London: Food Standards Agency, 2002.

26. Nelson M, Erens B, Bates B, et al. Low Income Diet and Nutrition Survey. Volume 1. Background, methods and sample characteristics. London: TSO, 2007.

27. Department of Health. Five a day pilot initiatives. Executive summary of pilot evaluation. London: Department of Health, 2002.

28. Del Tredici A, Joy A, Omelich C, et al. Evaluation study of the California Expanded Food \& Nutrition Program. J Am Diet Assoc 1989;89:1656.

29. Buller DB, Morrill C, Taren D, et al. Randomized trial testing the effect of peer education at increasing fruit and vegetable intake. J Nat Cancer Inst 1999;91:14911500.

30. Gerrish C, Mennella J. Flavor variety enhances food acceptance in formula fed infants. Am J Clin Nutr 2001;73:1080-5.

31. Birch L, McPhee L, Shoba B. What kind of exposure reduces children's food neophobia? Looking vs. tasting. Appetite 1987;9:171-8.

32. Savage SAH, Reilly JJ, Durnin JVGA, et al. Weaning practice in the Glasgow Longitudinal Infant Growth Survey. Arch Dis Child 1998;79:153-156.

33. Anderson AS, Guthrie CA, Alder EA, et al. Rattling the plate - reasons and rationales for early weaning. Health Educ Res 2001;16:471-479.

34. Watt RG, Dowler E, Hardy R, et al. Promoting recommended infant feeding practices in a low-income sample - randomised controlled trial of a peer support intervention. London: Food Standards Agency, 2006. 